\title{
Research on Consumer Behavior Based on the Perspective of Behavioral Economics
}

\author{
Litao $\mathrm{Xu}^{1, *}, \dagger$, Xinzhou Shen ${ }^{2, \dagger}$ \\ ${ }^{1}$ Ningbo Hanworth Kent School, Nibo, Zhejiang, 315200, China \\ ${ }^{2}$ Saint Michael University School, Victoria, British Columbia, V8P 4P5, Canada \\ *Corresponding author. Email: gaoming@cas-harbour.org \\ $\dagger$ These authors contributed equally.
}

\begin{abstract}
Consumers' rational behaviors usually only exist in the premises and assumptions of various traditional economics. On the contrary, consumer behaviors that are regulated as abnormal or irrational by traditional theories often appear in actual consumption activities. At present, in order to better study consumer behavior in reality, behavioral economics is an indispensable tool. Taking behavioral economics as a perspective, this article mainly focuses on irrational decisionmaking. It studies various theoretical results of behavioral economics, especially how prospect theory and mental account theory affect consumer behavior, and gives a strong operability and Realistic marketing strategies and marketing suggestions. Prospect theory mainly studies how consumers face the uncertainty of choice, and consumers are more sensitive to losses than gains. The main result of the anchoring effect is the understanding that consumers may make wrong decisions due to the influence of the reference point. Mental account theory explains the classification methods of consumer internal accounts with different bookkeeping methods and calculation forms. Consumers' behavior will be affected by multiple effects, so companies also need to consider multi-faceted marketing strategies at the same time.
\end{abstract}

Keywords: Behavioral economics; consumer; consumer behavior; mental account theory; prospect theory

\section{INTRODUCTION}

Throughout the history of consumer behavior research, consumer choice and decision-making have always been the focus of consumer behavior research, and the most central issue is "how consumers make decisions"[1].

With the rapid development of my country's market economy, research and analysis on consumer behavior have made great progress from the early 20th century to the late 1970s. As a result of drawing on a large number of Western research results, my country's consumption theory has gradually formed its own research system after being close to my country's characteristics and combining actual conditions.

Consumer behavior refers to the study of the process by which individuals or groups select, purchase, use, and process products or experience services, and it is usually to meet needs and expectations. Consumer behavior research has evolved from the initial motivation research to the most important research on consumer decision- making since the beginning of the American business community in the early years. However, because of the wide application of the Internet and mobile terminals after 2000, consumer behavior itself and the analysis of consumer behavior The method has also undergone a fundamental change[2].

After continuous development, consumer decisionmaking has quickly become the core issue of consumer behavior research, and various consumer decisionmaking models have also been born under the efforts of scholars. The new category in the Wiki entry that considers behavioral science and consumer research to be more comprehensive is consumer behavior research. Various theoretical explanations of human behavior, especially the behavior of human cognitive learning, belong to the category of behavioral science.

This article is based on the research of consumer behavior from the perspective of behavioral economics, researches consumer behavior based on the subject content of behavioral economics and consumer behavior, and conducts theoretical analysis of consumer behavior 
based on the research results of behavioral economics, supplemented by social surveys Take the data as an example for practical analysis.

Firstly, in the analysis stage, summarize and analyze existing results in related fields by using literature search. The focus is to understand and appreciate the theoretical ideas of the predecessors, compare the latest progress in behavioral economics at home and abroad, and try to use the research in this article[3]. As an innovation office in behavioral economics and consumer behavior research.

Secondly, in the research stage, theory and practice will be combined. What is more, the theoretical results of behavioral economics will be used to explain and analyze consumer behavior in real life, grasp the core characteristics of consumer behavior, and supplement the marketing of certain businesses by social surveys. The strategic result data analysis focuses on the overall analysis and does not ignore the individual situation. Theoretical analysis and practical analysis complement each other. The actual purchase behavior of consumers is studied through marketing cases, experimental results and life experience observations.

\section{ANALYSIS}

\subsection{Analysis of Consumer Behavior Characteristics under Situational Theory}

In the achievements of cognitive psychology, the psychological factors that make consumers show irrational decision-making and behavior, such as anchoring effect, cognitive disagreement, frame dependence deviation, etc., are all taken by Daniel Kahneman and Tversky. Theoretical guidance. After running the corresponding economic model, consumer decision-making results that are completely different from the assumptions of traditional economics are obtained.

Prospect theory is the development of expected utility theory. It is different from the expected utility theory of traditional economics, which believes that the absolute value of people's utility is equal between equal amounts of "gains" and "losses." The "gains" and "losses" with the same absolute number make different subjective value evaluations[4].

Firstly, people tend to hate returns. They always maintain a cautious and humble attitude before the harvest, worrying about the lost harvest. Therefore, the general investor's mentality is to take profit. In this experiment, people choose between buying two lottery tickets[5]. A lottery ticket is $100 \%$ worth 200 yuan, the probability of a B lottery ticket being scratched by 600 yuan is $1 / 3$, and the probability of $2 / 3$ is thanks for oner patronage. The expected value of this lottery is the same, but the A lottery is still the choice of most people. In addition, from the perspective of loss preference research, most people will not stop in front of the sacrifices that have already begun, hoping to make up for losses with greater risks. For example, let people choose between two treatment options. Option A can only heal $20 \%$ of the body. Option B has a $2 / 3$ probability of being invalid, but a $1 / 3$ probability of healing the body $60 \%$. The results showed that most of the subjects chose option B. Finally, most people are more sensitive to loss than gain[6]. When the same amount of money is gained or lost, the pain caused by the loss will be greater than the happiness gained.

Taking the consumer's risk aversion psychology into account, businesses should ensure that the discounts and conditions of promotional activities are clear and clear, and give consumers a full sense of security. There is also to ensure the reliability of marketing strategies. Once certain marketing activities have started, do not change or even cancel them easily. This is because path dependence and consumer psychology, which are more sensitive to losses, will make consumers feel that they have suffered losses after changing their strategies, thereby reducing their trust in businesses. Some negative examples are the hidden thresholds for various discounts in Double Eleven events in recent years[7]. The coupon ratio and discount strength are not directly proportional to the speed of panic buying. Such marketing activities will arouse consumer disgust and lead to low sales.

\subsection{Consumer behavior characteristics under anchoring effect}

The so-called anchoring effect means that when people quantitatively evaluate and determine an event, a specific value as the initial value constrains the measured value like an anchor restraining ship. The reason for the wrong decision-making judgment is also because the final measured value is getting closer and closer to the initial anchor value. The first to propose the concept of anchoring effect was Tversky. He set up a way for subjects to compare the number of United Nations African member states with a number (completely random) obtained by spinning the roulette, and then let the subjects guess How many experiments by UN member states in Africa. Although this random number obviously has nothing to do with the answer requirements, it still affects the subjects' answers to other questions. This is the anchoring effect, and the anchoring is a random number. The anchoring effect is widely present in various economic behaviors and consumer decisionmaking behaviors. People will consciously or unconsciously change their decision-making judgments due to the influence of the anchoring effect in various situations.

The anchoring effect is applied to the study of the influence of consumption goals on consumer judgment and decision-making. There are two types of consumption goals. Utilitarian goals are concerned with 
the functionality of consumption, but hedonic goals are concerned with the pleasure brought by consumption. Consumers do not only pay attention to one goal, but often prefer to seek a balance between hedonic and utilitarian, hoping that consumption activities can satisfy both at the same time. However, there are many studies that show that under the same consumption scenario, the subjects will always use the first choice as an anchor when making the next choice. Most of the subjects prefer to tilt a certain goal rather than balance again. This means that when the first choice is used as an anchor, when the assimilation effect is superior, the consumer's choice is more biased; when the contrast effect is superior, the consumer will strive to achieve a balance.For example, from the perspective of brand effect, when a new brand is listed, it will directly target well-known brands with similar products, such as the choice of store shelves and packaging design, as close as possible to well-known brands, and use its anchoring effect to promote. Studies have shown that there is a significant negative correlation between consumers' familiarity with the brand and the anchoring effect it brings, that is, the more familiar the brand, the weaker the anchoring effect of the brand, and the less attractive and sticky it will be to consumers. This reminds us that after the brand has a certain degree of recognition and familiarity, update products in a timely and continuous manner to enhance the anchoring effect of the brand's continued attractiveness to consumers.

How do consumers form and adjust their own internal reference prices? Two researchers studied how the external sales price of a product affects the internal reference price of consumers. In this case, the external sales price is equivalent to an anchor point. Rajesh and Dhruv found that the degree of difference between the external sales price of a product and the internal reference price determines the degree of impact. When the internal reference price is lower than the external sales price, the internal reference price will have upward pressure to change the anchor value; when the internal reference price is higher than the external sales price, the consumer's price satisfaction will increase accordingly . In reality, product advertisements or packaging will indicate the recommended price, and many consumers will adjust the internal reference price based on this price as an anchor point. This shows that manufacturers can increase the internal reference price of consumers accordingly by increasing the list price or reference price of the product. In other words, after using the external quotation as an anchor point, consumers can increase their valuation of the product through the consumers' psychology of saving money.

The anchoring effect also has an inverse effect. After studying online auctions, some scholars have concluded that an auction with a relatively small starting price will have a relatively large transaction price in the end, that is, a low anchor causes a high anchor. One of the possibilities for the anchoring inverse effect is that the auction threshold has become lower due to the relatively small starting price, which leads to the expansion of the sales market and the participation of more participants. Besides, it is accompanied by a gradual increase in transactions. The number of times, a relatively small opening price will bring more sunk costs, so as to lead to a higher price auction results.

\subsection{Research on Consumer Behavior Characteristics under the Theory of Mental Accounts}

Mental accounts are the process by which people mentally classify, code, keep accounts, estimate and budget for various results, which are mainly economic results. The exact definition of this concept was derived from Kahneman's psychological research, but the finalized theory was researched by Thaler, a professor of behavioral sciences. The theory of mental accounts means that the scope of mental accounts includes individuals, families or enterprises, and its algorithm is not similar to the algorithm of traditional economics. It changes decision-making judgments in ways that are not expected by people. Everyone has mental accounts in their minds, and as a result, they will make decisions that are quite different from the "rational" in traditional economic people.

According to the mental accounting theory, there are two essential characteristics of consumer behavior that are summarized, including non-substitution and compliance with specific algorithms. At the same time, it also shows the irrational characteristics of consumers.

The income from inconsistent sources considered by traditional economics is of the same nature and can be completely replaced. In real life, the income of mental accounts is classified into different accounts due to their inconsistent sources. This is the non-substitution effect. Through the observation of real life, it can be concluded that "flying windfall" and "selling money" belong to different mental accounts and are non-substitutable. The money in the "selling money" mental account will be well preserved and belong to "flying windfall". "The income will be thrown away.

The fundamental reason for the existence of nonsubstitution is because mental accounts will have different account structures due to their different characteristics. Expenses for different purposes are grouped into different accounts; income from different sources is grouped into different accounts; different ways of savings are grouped into different accounts.

Expenses for different purposes are grouped into different accounts, which can be illustrated by an experiment[8]. Suppose there is a drama tonight, and the ticket price is 300 yuan. Before one set off, one found that the 300 yuan clothes one just bought were lost, so would one continue to watch the drama? Most of the subjects 
indicated that they would go to the drama. But if one lose the ticket for the drama before one leaves, one have to buy a new ticket if one want to watch it, which means one spend another 300 yuan, would one be willing? The results showed that most subjects would not buy a ticket again and watch it again. This shows that although the money is the same, the expenditures for watching dramas and new clothes are classified into different mental accounts by people. If one buy more tickets, it is equivalent to watching a drama at 600 yuan. The change in cost performance affects people's decision-making.

The "banker's money effect" can well illustrate that different sources of income are classified into different accounts. When gamblers win money, they will separate the winning money and the principal into two accounts, and the principal will not move easily. But the money won will be put into the "get it for nothing" account, thinking that it is the money of the dealer, it will be squandered or risked into the next bet.

Different types of savings are classified into different accounts. The funds in the fixed account will not be used to meet the expenditures of temporary projects. For the expenditures of temporary projects, high-interest loans are often chosen. For example, some people would rather use interest-bearing loans in certain emergency situations than misappropriate their deposits.

\section{CONCLUSION}

The above analysis of behavioral economics theory has explained the irrational characteristics of consumers, and fully demonstrated the irrational characteristics of consumers from different aspects. Each theory has its focus. The prospect theory focuses on explaining how consumers face the uncertainty. The anchoring effect believes that in the choice of gains and losses, consumers will start from the outside world or themselves. Information is used as a basis to adjust one's cognition of things, both of which are estimates and judgments when the research has not yet obtained economic results. In addition, mental accounts are classified and calculated based on the differences in expenditure, income, storage methods, etc. when the dust of economic results settles. The endowment effect explains the phenomenon of people's preference for the things they own.

The above is an analysis framework of consumer behavior influencing factors based on the perspective of behavioral economics, and how to use these theories to influence consumer behavior is what enterprises and merchants care most about. Consumer behavior often has a comprehensive effect of the above multiple psychological effects. In order to obtain better and more efficient marketing effects, manufacturers and enterprises should also develop marketing strategies or marketing behaviors from multiple angles and aspects, and conduct marketing as comprehensively as possible. Activity.
Firstly, once the marketing plan is determined, it should not be changed easily. When the existing marketing plan is changed, the comparison between the marketing plans should also be shown, so that consumers can choose the preference according to the reference point in the comparison; word-of-mouth marketing must be done well, because Consumers prefer the probability of small events. When the marketing information is obtained by consumers from people around them, the sales rate will also increase.

Secondly, companies should make good use of the role of anchors. The anchoring effect may change consumers' desire to buy, pay, and preferences. When formulating marketing strategies, manufacturers and enterprises can use differentiated strategies to strengthen the role of anchors, expand their brand awareness, attach importance to and strengthen the construction of anchor systems, which will make consumers have path dependence, and form purchase inertia of products.

Thirdly, due to the non-substitution of mental accounts and the characteristics of specific algorithms, especially the endowment effect and sunk cost effect, in order to give full play to the emotional account effect of consumers, attention should be paid to the role of festivals in increasing sales. The measures to increase prices and reduce discounts must be taken. Then multiple discount promotion strategies in stages must be implemented. Due to the sunk cost effect, membership fees, pre-charged cards and other methods can be used to reduce the cost of consumers already paid sensitivity.

\section{REFERENCES}

[1] Knetsch J L. The endowment effect and evidence of nonreversible indifference curves. American Economic Review, 1989, 79(5):1277-1284.

[2] Harbaugh W T, Krause K, Vesterlund L. Are adults better behaved than children? Age, experience, and the endowment effect. Economics Letters, 2007, 97 (2) : 128-132.

[3] Marsan G A . New paradigms towards the modelling of complex systems in behavioral economics[J]. Mathematical \& Computer Modelling, 2009, 50(34):584-597.

[4] Thaler R H, Benartzi S . Save More Tomorrow (TM): Using Behavioral Economics to Increase Employee Saving[J]. Journal of Political Economy, 2004, 112.

[5] Foxall G R, Oliveira-Castro J M, Schrezenmaier T C . The behavioral economics of consumer brand choice: patterns of reinforcement and utility maximization[J]. Behavioural Processes, 2004, 66(3):235-260. 
[6] Foxall, Gordon R. Behavioral Economics in Consumer Behavior Analysis[J]. Behavior Analyst, 2017:1-5.

[7] Volfova H, Salamoun J, Bergami R. Rationality of University Students: A Behavioral Economics and Consumer Behavior Perspective[J]. International Journal of Interdisciplinary Studies in Communication, 2015.

[8] Wang K, Salehin M F, Habib K N. A Discrete Choice Experiment on Consumer's Willingness-to-Pay for Vehicle Automation in the Greater Toronto Area[J]. Transportation Research Part A Policy and Practice, 2021. 